\title{
WestVirginiaUniversity
}

THE RESEARCH REPOSITORY @ WVU

Graduate Theses, Dissertations, and Problem Reports

2014

\section{Normal Violence: The Case of Fighting on a College Campus}

\author{
Brent Boyd \\ West Virginia University
}

Follow this and additional works at: https://researchrepository.wvu.edu/etd

\section{Recommended Citation}

Boyd, Brent, "Normal Violence: The Case of Fighting on a College Campus" (2014). Graduate Theses, Dissertations, and Problem Reports. 365.

https://researchrepository.wvu.edu/etd/365

This Thesis is protected by copyright and/or related rights. It has been brought to you by the The Research Repository @WVU with permission from the rights-holder(s). You are free to use this Thesis in any way that is permitted by the copyright and related rights legislation that applies to your use. For other uses you must obtain permission from the rights-holder(s) directly, unless additional rights are indicated by a Creative Commons license in the record and/ or on the work itself. This Thesis has been accepted for inclusion in WVU Graduate Theses, Dissertations, and Problem Reports collection by an authorized administrator of The Research Repository @ WVU. For more information, please contact researchrepository@mail.wvu.edu. 
Normal Violence: The Case of Fighting on a College Campus

\author{
Brent Boyd \\ Thesis submitted \\ to the Eberly College of Arts and Sciences \\ at West Virginia University \\ in partial fulfillment of the requirements for the degree of \\ Master of Arts in \\ Applied Social Research
}

\author{
Joshua Woods, Ph.D., Chair \\ Rachel Stein, Ph.D. \\ Jesse Wozniak, Ph.D. \\ Department of Sociology and Anthropology
}

\title{
Morgantown, West Virginia \\ 2014
}

Keywords: normalization of violence, deviance, fighting, psychological harm, situations, gender

Copyright 2014 Brent Boyd 


\section{ABSTRACT \\ Normal Violence: The Case of Fighting on a College Campus}

\section{Brent Boyd}

Researchers have proposed a number of theories to explain how violence becomes normalized and thereby increases the incidence of violent acts. This study explores these theories using the case of interpersonal violence on the campus of a large, Mid-Atlantic university. During the 2012-2013 academic school year, undergraduate participant observers witnessed 150 altercations, and gave detailed descriptions of when and where each altercation occurred, who was involved in them, and what consequences resulted. They also described their thoughts and feelings as they witnessed the physical altercation. Some witnesses reported experiencing fear, distress and sorrow, others experienced no adverse cognitions or emotions, while still others felt amused or entertained. Using bivariate and multivariate analyses, we examined several variables that may explain why the witnesses' psychological reactions varied. These included the gender and age of the witnesses, the extent of physical injury to the fighters, as well as several situational variables such as the time and place of the altercation and the social composition of the bystanders. The study showed that psychological reactions to college fighting were explained by individual, trait-based differences between the witnesses, as well as by variation in the specific situations where the altercations occurred. Drawing on dispositional and situational perspectives, a theory of normal violence is proposed. 


\section{TABLE OF CONTENTS}

CHAPTER 1: INTRODUCTION .................................................................

CHAPTER 2: THEORETICAL FRAMEWORK........................................................2

CHAPTER 3: METHODOLOGY .......................................................................

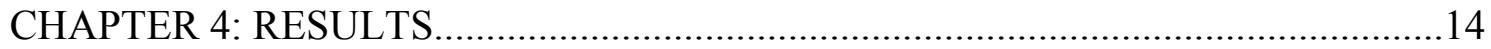

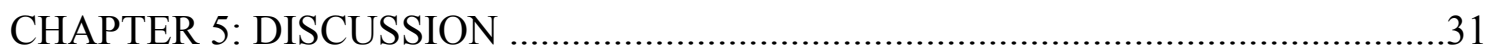

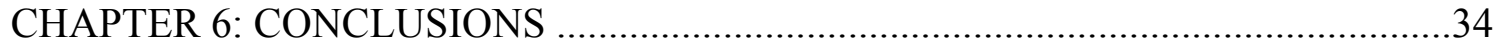

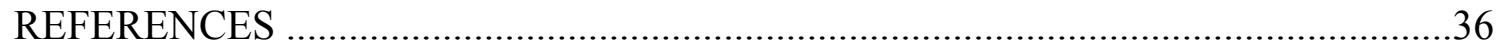

APPENDIX A: QUESTIONNAIRE FOR PARTICIPANTS

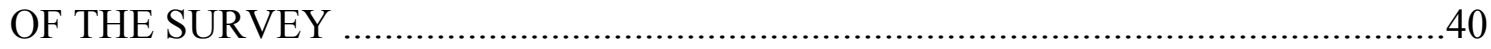


There are few behaviors more regrettable than violent ones. Denounced by activists, faulted by philosophers and prohibited by law and religious principle, the use of physical force against others is broadly perceived as immoral and unacceptable. In spite of the legal and normative proscriptions, however, violent disputes occur frequently in daily life and are sometimes regarded as typical, acceptable, justified or even amusing. The process through which violence becomes normal has interested social scientists of all stripes. Concern for this topic derives most directly from the known positive correlation between the normalization of violence and the use of it during conflicts. However, a lack of research exists specifically studying college students. As discussed in greater detail later, we use the term "normal" broadly to categorize a range of non-negative or positive reactions to interpersonal violence.

In this study, we examine the case of interpersonal violence on the campus of a large, Mid-Atlantic university during the 2012-2013 academic school year. Undergraduate participant observers witnessed 150 altercations, gave detailed descriptions of each altercation, and described their thoughts and feelings as they witnessed the physical altercation. Some witnesses reported experiencing fear, distress and sorrow, while others experienced a variety of nonnegative cognitions and emotions.

Drawing on previous studies, we test four theories that may explain the students' reactions to the violent incidents. Following the null hypothesis, we begin with the idea that violence is generally not perceived as normal, and that any variance to it simply reflects the variance in the intensity of the given altercation and the physical harm experienced by the fighters. We expect to see this tendency in all student observers, regardless of their age or gender. Second, we test the assertion that for certain populations of people (i.e. college students), violence becomes normal over time. As students become older and delve deeper into the college subculture, they become accustomed to violence during the course of their academic careers. Third, we investigate the assumption that gender socialization produces more acceptance of violence among men than women.

In contrast to these trait-based perspectives, our fourth theory focuses on the situational characteristics and micro-social settings in which altercations occur. Taken together, the various studies of "normal violence" make it clear that certain situational characteristics pertaining to geographical location, day and time, and organizational context play key roles in determining whether people experience non-negative reactions to violent acts. 
This study is exploratory in nature, with our main goals being to describe the situational characteristics of college fighting and demonstrate whether these variables are meaningful predictors of people's reactions to it, controlling for the trait-based variables noted above. Our study shows that psychological reactions to college fighting are explained by individual, traitbased differences between the witnesses, as well as by variation in the specific situations where the altercations occurred.

\section{THEORETICAL FRAMEWORK}

Norms Against the Use of Violence

Criminality is a necessary function of society by influencing the way in which society progresses. Our first argument is that while crime and violence are inevitable norms in societies today, norms against the use of interpersonal violence exist under certain circumstances. We frame this argument around the work of Emile Durkheim and his book, The Rules of Sociological Method.

Throughout human history criminality, specifically in our case violence, has always existed, but not in the same form everywhere. According to Durkheim (1982), its form changes; the acts thus characterized are not the same everywhere; but, everywhere and always, there have been men who have behaved in such a way as to draw upon themselves penal repression.

Crime is necessary because it is apart of the fundamental conditions of all social life. These conditions are indispensible to the normal evolution of morality and law. Where crime exists, collective sentiments within society are flexible to take on a new form, thus crime sometimes helps to determine the form societies evolve into (Durkheim 1982). Therefore, as societies evolve, the moralities of acts that are acceptable and not acceptable also evolve.

Due to its influence in the evolution of societies, criminality is a normal function within society. Criminality is normal because a society exempt from it is utterly impossible (Durkheim 1982). However, we argue that criminality becomes abnormal when it exceeds a certain level deemed acceptable in the society in which it takes place. In order to criminal acts to be deemed abnormal, they must be impossible to fix in conformity with the preceding norms (Durkheim 1982). 
For this study, we argue that the severity of violence plays an integral role in the normality of violence on college campuses. When the severity of violence from fighting exceeds the acceptable limit, it will be viewed as abnormal.

We arrived at the previously stated argument in part because the severity and frequency of violence has decreased over time. According to Durkheim (1982), in former times, acts of violence against the person were more frequent than they are today. In his book The Better Angels of Our Nature, Pinker (2011) corroborates Durkheim's perspective by arguing that contrary to the popular belief of today's citizens, the world is a much less violent place than it was a couple hundred years ago. Pinker makes a bold claim that "a contemporary Englishman has a 50-fold less chance of being murdered than his compatriot in the Middle Ages."

According to Pinker (2011) the decline in societal violence is attributed to what he calls "The Pacification Process". This process describes the evolution of the human race from huntergatherer tribes to civilized state-based societies. As this transition occurred, the need to commit violent acts against other individuals diminished. Governments now outlaw acts that were once a necessity for one's survival. These laws are designed to render a harsher punishment as the severity of the violence increases because severe acts of aggression are seen as non-normal by today's societal standards.

In sum, we argue that while crime has always existed as a necessary function, the use of violence to settle disputes has diminished throughout the progression of society. Lower levels of violence are now the norm, while high levels of violence have since become abnormal. To test this, the Physical Harm variable differentiates between minor harms and major harms resulting from the fights observed. Using the above theoretical framework, we hypothesize:

- H1a. Fights resulting in minor physical harm will be viewed as normal more often than fights resulting in major physical harm.

- H1b. Fights resulting in major physical harm will be viewed as disturbing more often than fights resulting in minor physical harm.

\section{Violence Becomes Normal Over Time}

While the frequency and severity of violence has lessened throughout society as a whole, there are groups within our society embedded within a culture of more severe violence. The second argument we make is that for college students, violence is not perceived as normal at 
first, but becomes normal over time, as students grow older. More specifically we argue that over time, students will learn norms associated with the college subculture and come to accept them as a normal part of their college experience.

I begin by explaining the subculture of universities using the subculture of violence model developed by Wolfgang and Ferracuti (1967). Subculture, defined by Wolfgang and Ferracuti (1967), is "a normative system of some group or groups smaller than the whole society." While college students behave according to the norms associated with the broader scope of the American culture, they also behave according to the norms associated within the college subculture. At times, the norms of the subculture may countercheck the norms of the larger culture.

According to Wolfgang and Ferracuti (1967), the overt use of violence is generally a reflection of basic values that stand apart from the dominant, the central, or the parent culture. This overt (and often illicit) use of violence constitutes part of a subcultural normative system that is reflected in the psychological traits of the members of the subculture. During the week, the norm for students is to be academic, focusing on studying and completing their schoolwork while abiding by the laws of society. Therefore, these norms reflect the basic norms/values of the dominant culture.

Once the weekend arrives, students' mentality alternates to the norms associated with the college subculture. The values, norms, laws, etc. associated with the college subculture primarily revolve around partying and the drinking of alcohol. To younger students the norms of the college subculture are new, and therefore younger students are inexperienced in the lifestyle associated with these subcultural norms. Due to this inexperience, younger students view violent altercations as non-normal as first, but as they grow older and more accustomed to the college subculture, they learn to accept acts associated with this subculture as normal.

The learning process college students experience is similar to research completed by Albert Bandura and his Social Learning Theory. According to Bandura (1971), in the social learning system, new patterns of behavior can be acquired through direct experience or by observing the behavior of others. Through repeated experiences (direct or by observation), college students learn the subcultural norms associated with the college lifestyle.

While learning the norms of the college subculture, students form a set of 'normative beliefs.' According to Huesmann and Guerra (1997), normative beliefs are defined as 
individualistic cognitive standards about the acceptability of a behavior. They should influence (and be influenced by) mental processing of events. Normative beliefs may or may not be consistent with the prevailing social norms, although there should be considerable overlap between an individual's normative beliefs and the normative beliefs of relevant peers, social groups, and societal institutions.

A study completed by Huesmann and Guerra (1997) found that both normative beliefs approving of aggression and actual aggressive behavior increase with age. This study supports the notion that as individuals get older, they become desensitized to violence due to the constant exposure available to them. In other words, while fighting may not be seen as a normal behavior by society as a whole, older students will form normative beliefs and accept this behavior due to their experiences while advancing from freshman to senior status.

In sum, we argue that as college students become older, the normality of violence on college campuses becomes more normal. To test this, the Respondent_Age variable is differentiates between observers who are under 21 years old and observers who are 21 years old or older. Using the above theoretical framework, we hypothesize:

- H2a. Older students will view fights as normal more often than younger students.

- H2b. Younger students will view fights as disturbing more often than older students.

\section{Violence is Normal for Men, Non-Normal for Women}

The third argument we make is that violence is normal for men, but not for women. Gender socialization in early life produces more acceptance of violence among men than women. In this study, I assess the normality of altercations according to the genders of the participant observers and the normality of altercations when only male participants are involved compared to when a female fighter is involved in the altercation.

Numerous gender stereotypes pertaining to fighting exist. Stark (2007) found that the belief amongst adolescents is that it is more likely for young men to use violence and abuse instrumentally. Mac an Ghaill (1994) found that the majority of young people in their sample held very 'traditional' attitudes towards female and male gender roles, with men regarded as the 'breadwinners' and women as care givers (McCarry 2010). Aggressiveness is a component of the masculine stereotype (Archer and Lloyd 2002) and is a part of the male identity (Campbell 1993). Aggression is the antonym of femininity because aggression is normal for men and 
deviant for women (Campbell 1993; Day, Gough, and McFadden 2003). Therefore male-only altercations are seen as more normal than altercations involving a female.

We also argue that men and women differ on their feelings upon witnessing a violent altercation. More specifically, women have a much stronger emotional reaction than men. Females are generally more empathic or sympathetic than males (Hoffman 1977; Feshbach 1982; Eagly and Crowley 1986) and provide (and receive) more emotional support than men (Vaux 1985). According to Austin (1979) further research shows a greater desire to help by females because of their heightened affective sensitivity, including empathy (Kilham and Mann 1974) and guilt (Wallington 1973).

Lowe et al. (2012) found that female violence presents concerns for female bystanders, such as feelings of interpersonal or group-based shame. Female fighting is discussed with angst and distaste, and for many interviewees, female fighting is upsetting because it undermines the idea of women as rational adults.

In sum, we argue that for men, it is more socially acceptable to settle disputes by committing aggressive acts. An indirect effect of this social acceptance for males is that men are more likely to see others fighting as more normal than women. To test this, the Fighters_Sex variable compares fights that only involve males and fights that include at least one female. Also, the Respondent_Sex variable differentiates between observers who are male and observers who female. Using the above theoretical framework, we hypothesize:

- H3a. Fights with only male participants will be viewed as normal more often than fights involving only female participants.

- H3b. Fights with only female participants involved will be viewed as disturbing more often than fights involving only male participants.

- H4a. Male observers will view fights as normal more often than female observers.

- H4b. Female observers will view fights as disturbing more often than male observers.

\section{Normality of Violence is Situational}

The last argument we make is that violence is normal in some situations, but not in others. Situational characteristics determine whether people experience non-negative reactions to violent acts. The situation is the immediate setting in which behavior occurs (Stebbins 1972; Moos 1973; Pervin 1978; Furnham and Argyle 1981; Magnusson 1981; Birkbeck and LaFree 
1993).

A study by Pich et al. (2010), for instance, showed that emergency-room nurses are victimized by verbal and physical abuse from patients so often that they have accepted it as "part of the job." Researchers have discovered a similar normative framework in other social work and hospital situations (Virkki 2007). Normal violence has been examined in many other specific contexts, including sports and recreational activities (Curry 1993; Bloom and Smith 1996; Roberts and Benjamin 2000), war zones (Borell 2008; Allen and Devitt 2012) and some innercity neighborhoods (Ng-Mak et al. 2002; Dunlap et al. 2009).

The most prevalent situational characteristic of this study is the party subculture of college, where alcohol is easily accessible. The effects of alcohol depend on the social contexts in which drinking occurs (Fagan 1990; Parker and Rebhun 1995). Alcohol may facilitate violence when adolescents are drinking with friends in an unsupervised setting (Rossow 1996) as well as increase the likelihood of retaliating with aggression once provoked (Bushman and Cooper 1990; Graham, Schmidt, and Gillis 1996; Exum 2006; Felson et al. 2011).

For this study, we look at the situational triggers that are primarily responsible for escalating the confrontation to physical blows. Many of these situational triggers can be categorized as "trivial" or fights about "nothing" (Griffiths, Yule, and Gartner 2011). When the use of alcohol is involved, it leads to misbehavior in cultures where alcohol is viewed as a form of "time out," i.e., where the normal rules of interaction are relaxed (McAndrew and Edgerton 1969) thus making trivial fights more socially acceptable.

Lastly, we look at situational settings within time and locational context related to the nighttime lifestyle. Previous studies show that nighttime activity is usually considered riskier when compared to daytime activity (Hindelang, Gottfredson, and Garofalo 1978; Messner and Tardiff 1985). Furthermore, the riskiness of nighttime activity increases when the frequency of nighttime activity outside the home increases (Miethe, Stafford, and Long 1987).

In sum, we argue that normality is related to situational characteristics pertaining to the college nighttime party culture involving heavy alcohol use. To test this, the variables: Situation_Trigger, Fighters_Intoxication, Time, Day, and Bystander_Number are analyzed. Also, situational characteristics pertaining to the overall composition of the fights and fighters can be used to predict the normalization of fighting. To test this, the variables: Fighters_Race, 
Fighters_Stature, Fighters_Willingess, Fighters_Numbers, Situation_Planned, and Fight_Fair are analyzed. Using the above theoretical framework, we hypothesize:

- H5a. Fights with situational characteristics related to the college subculture and fair fighting will be viewed as normal more often than disturbing.

- H5b. Fights with situational characteristics not related to the college subculture and unfair fighting will be viewed as disturbing more often than normal.

\section{METHODOLOGY}

While research on interpersonal violence is extensive, very few if any studies have examined the unique case of college fighting and no studies to our best knowledge offer observational data on altercations as they naturally occur. For this reason, we began this project in the spirit of discovery rather than verification. Our case-oriented analysis is designed to offer a detailed and in-depth portrait of this behavior as opposed to providing universal statements about one or two main factors that cause interpersonal violence (Ambert et al. 1995). A qualitative, observational design is appropriate for research when the goals are to develop social concepts, identify relevant variables and determine behavioral patterns (Babbie 2008).

\section{Sample}

During the 2012-2013 academic school year at large, Mid-Atlantic university, undergraduate students from five upper-level sociology courses were recruited to serve as participant observers of violent altercations on or near the campus. Approximately two hundred

forty students were registered in these five sociology courses, and from these students, one hundred fifty participated as field observers. In order to conduct the research of fighting on a university campus, college students were the logical choice for the unit of observation due to relevance and convenience. According the College Portraits website (2012-2013), the large, MidAtlantic university in this study is home to almost thirty thousand graduate and undergraduate students. Of these thirty thousand students, forty-six percent are female and fifty-four percent are male. The race of the student population is mostly homogenous with eighty-five percent being Caucasian while the remaining races range between one percent (Native American) and four percent (Black). The average age of the student population is twenty-one years, and twenty-eight percent of students come from low-income households. 


\section{Survey Procedures}

Before entering the field, the students learned the basics of participant observation research and became familiar with a set of questions pertaining to when and where altercations occurred, who was involved in them, and what happened before, during and after the given altercation. The final question was aimed at learning about the participant observer's thoughts and feelings as they witnessed the altercation. All the questions were open-ended and the observers were urged to give as much detail as possible in their written responses. Following the altercation, the observers were required to write down their responses as soon as possible and no later than 48 hours after the incident. The volunteers were offered a small amount of extra credit for participating. They were warned repeatedly not to look for altercations or change their usual routines in any way. An alternative extra credit assignment was offered to those who did not happen to witness an altercation in their day-to-day life during the given semester or who did not wish to participate in the study.

The design of this study is unique in that students were required to report the witnessed altercation within forty-eight hours. Past studies on fighting have asked individuals to recall information of altercations witnessed much further into the past. The time frame in which the altercations must be reported coupled with the open-ended design of the survey allows for the researchers to analyze the altercations with a "first-hand" account mentality.

\section{Survey Instrument}

An inter-coder reliability check was performed before analysis of the data began. Two researchers (a tenure-track professor and Master's student) coded each variable, with the initial check having an agreement ranging from $90 \%$ to $100 \%$. For those units in disagreement, the researchers discussed the differences in their coding categorizations. A mutual agreement on all coded variables was reached in order to give consistent measurements throughout the data.

Psychological harm is indicated by the responses the participant observers gave about their initial feelings about the fight they witnessed. The first categorization is 'Normal/No Effect.' This categorization was given when observers actually wrote that the fight did not affect them, and/or that it happens all the time, and/or it was no big deal. For example, common responses were similar to these students' reactions: "I wasn't very affected at all, I witness fights 
like this a lot, especially when people are drinking" and "this fight did no affect me at all. It was just another usual night in Morgantown."

The second categorization is 'Disturbing.' This categorization was given to observers' responses which referenced several different types of negative affects, such as: "very worried," "scared," "terrified," "startled," "alarmed," "very uncomfortable," "terrible to see," "upset," "anxious," "nervous," "affected badly," "sad," "shocked," "messed up". For example, an observer who was disturbed by a fight responded that: "I was upset that there was a fight. I went out to have a good time and the party I went to was ruined over a very pointless fight."

The third categorization is 'Other.' This categorization was given to observers' responses, which referenced a wide range of neutral or positive reactions, such as: "interesting," "enlightening," "funny," and "entertaining". For example, a common response categorized as 'other' was: "I was ashamed that during a football game where we are all cheering our team on that a fight would occur."

For the data analysis, the psychological harm variable was split into two dichotomous variables. The first variable Harm_Normal was categorized by fights that were seen as normal or had no affect on the participant observers and all other responses on how the participant observers were affected by the fight they witnessed. The second variable Harm_Disturbing was categorized by fights that had negative affects on the participant observers and all other responses on how the participant observers were affected by the fight they witnessed. Figure 1 demonstrates the breakdown of the psychological harm variable:

Figure 1: Psychological Harm on Observer

\begin{tabular}{lccr}
\hline \hline & Frequency & Percent & $\begin{array}{c}\text { Cumulative } \\
\text { Percent }\end{array}$ \\
\hline Normal/No Effect & 57 & 38.0 & 38.0 \\
Disturbing & 43 & 28.7 & 66.7 \\
Other Responses & 50 & 33.3 & 100.0 \\
Total & 150 & 100.0 & \\
\hline \hline
\end{tabular}


Physical harm is indicated by the responses the participant observers gave about the end consequences of the fight they witnessed. The first categorization is 'Minor Harm.' This categorization was given to fights containing small pushing matches where there is very little pain distributed or fights where a few punches thrown but no visible signs of pain, such as blood. For example, a typical response coded under the 'minor harm' categorization was: "No one was injured and it appeared to only be an argument between the two males."

The second categorization is 'Major Harm.' This categorization was given to fights containing visible signs of pain, such as: blood, ripped cloths, numerous punches to the face as well as knockout punches, broken bones, and the need for hospital visits. The following participant observer witnessed a fight in which major harm occurred to one of the fighters: "My male friend who was hit with the wooden plank had a broken nose and jaw, and had to go to the emergency room."

Some observers say there was "no harm done" but they also describe injuries, such as a bloody nose; their descriptions of what injuries occurred is what was coded, not their interpretations of the amount of injury. Whenever an observer did not describe in detail the injuries sustained from the fight, we coded according to our estimated level of harm resulting from actions taken during the fight (i.e. getting hit with a beer bottle, receiving several punches, being thrown across the room, etc.).

Respondent_Age is indicated by the responses the participant observers gave when asked to input their age on their fight observation. This variable was coded into two categorizations: 'under 21 ' and ' 21 and over.' This age cutoff was chosen because twenty-one signifies a student's transition from lower-classman status to upper-classman status.

Gender ${ }^{1}$ is indicated by the responses the participant observers gave about their own gender and the genders of the fighters. Respondent_Sex measures the gender of the observers and is categorized by 'male' or 'female.' Fighters_Sex measures the fighters' genders and contains two categorizations. The first categorization is 'Female vs. Female.' Fights coded into this category contained only female fighters. The second categorization is 'Male vs. Male.' Fights coded into this category contained male fighters only with no physical acts committed by a female.

\footnotetext{
${ }^{1}$ The third categorization for Fighters_Sex, 'male vs. female,' is not included in the analysis due to such a small number of units (less than 5).
} 
Situational characteristics are indicated by responses the participant observers gave pertaining to various aspects of the setting in which the fight occurred. The First set of variables describes patterns involved within a college party culture context.

The variable Situational_Trigger identifies the primary reason for the escalation to physical fighting. It is categorized as: 'minor physical harms' (fights that start over two people bumping into one another), 'status gain' (competitions or money-related issues), 'romantic relationships' (jealousy-related), and 'individual/social identity' (degrading comments about the fighter's social group or physical aspect of the fighter). Students were asked to give reasoning as to why the violent altercation escalated. This example of a student's response was coded as 'individual/social identity': "I witnessed the start of the fight firsthand: before the physical fight began, one of the males by accidentally spilled beer on the other males new sneakers. The male who got the beer spilt on him called the other male an "alcoholic pussy". The male responded by saying " I own your mothers pussy". The male got extremely mad and gave him the middle finger and smacked the male's cellphone out of his hand to the ground."

The variable Fighters_Intoxication measures the intoxication levels of each side participating in the fight. The three categorizations are: 'None/Low,' 'One Side Intoxicated,' and 'All Sides Intoxicated.' These categorizations were measured based on details given about the prior drinking habits and/or body language of the fighters. The following response was categorized as 'All Sides Intoxicated': "Yes. the two fighters appeared to be intoxicated. Both contained slurred speech and bad reaction times. One of the fighters also could not make eye contact with other individuals."

The variable Time measures the amount of fights occurring in the 'Daytime' and 'Nighttime'. The participant observers were asked to estimate the time in which the fight occurred. Day and night are defined by mean sunrise and sunset times. In Charleston WV, on average, the sun sets at $7 \mathrm{pm}$ and rises at $7 \mathrm{am}$. Therefore 'Daytime' is defined as the 12-hour period between 7 am and $7 \mathrm{pm}$, and 'Nighttime' is defined as the opposite period, 7:01 pm to 6:59 am. 
The variable $D a y^{2}$ measures the amount of fights that occurred on 'School Days' (Monday-Thursday) and 'Weekend Days' (Friday thru Sunday). Monday through Thursday is traditionally seen as the days in which students primarily focus on their academics, while Friday signifies the start to the weekend off from school.

Lastly, Bystander_Number measures the amount of people present during the fight, as given by the participant observer. This variable is categorized as: 'A Few' (1-5 people), 'A Small Crowd' (6-10 people), and 'A Large Crowd' (More than 10 people).

The second set of variables describes patterns pertaining to characteristics of the fighters. Fighters_Race measures the races of the each of the fighters involved, given by the participant observer. This variable is categorized as 'White vs. White' and 'White vs. Other Minorities.'

Fighters_Stature measures the body structure of each of the fighters in terms of size and perceived strength. This variable is categorized as 'Symmetrical' and 'Asymmetrical.' A response coded as asymmetrical is: "One of the guys was at an advantage mainly due to the fact he was a little muscular, and was at an advantage when they got into a fight."

Fighters_Willingness measures whether or not all the fighters were equally willing to fight. This variable is categorized as 'Symmetrical' and 'Asymmetrical.' A response coded as asymmetrical is: "One fighter wanted to fight and the other didn't which lead to the one holding the other in a headlock and asking for help from police."

Fighters_Numbers measures the amount of fighters on each side. This variable is categorized as 'Symmetrical' and 'Asymmetrical.'

Situation_Planned measures whether or not the observer perceived the fight as being 'Unplanned/Spontaneous' or 'Planned/Retaliation.' The main difference is probably the extent to which the fight escalates; some fights might seem "out of the blue" while most build up with each side criticizing the other. A response coded as planned/retaliation is: "The game was won by the two younger players who immediately began to curse and shout at the older player as a result of the continuous in-game taunts by the older player. The older player then approached the two younger players. He got into their faces and started cursing at them as well. As a result, the two younger players tackled him and began to attack him with punches and kicks."

\footnotetext{
${ }^{2}$ Day is coded according to the which day the activities leading up to the fight started (i.e. a fight that occurred at 1a.m. on Friday was coded for Thursday since students consider that time to be Thursday night.
} 
Using the above variables pertaining to the fighters involved, the participant observers were asked: "Was the fight fair?" From this question, the variable Fight_Fair was created, and measures the observers' perceptions on why they thought the fight was fair or not. The observers' responses are categorized as either 'fair' or 'unfair.' For example, the response: 'All individuals in the fight were around the same age and size while each group had three members so it was 3v3" was categorized as 'fair' while the response: "No, the first male was taller and a little bigger the second male took the first punch but it was obvious after a minute that the first male was much stronger" was categorized as unfair.

\section{RESULTS $^{3}$}

\section{Norms Against the Use of Violence}

Table 1.1 compares the amount of fights viewed as normal and the level of physical harm resulting from the fights. According to table 1.1, 40\% of fights with minor physical harm were viewed as normal compared to $34 \%$ of fights with major harm. This figure is not statistically significant $(\mathrm{p}=.291)$, therefore we reject hypothesis H1a (fights resulting in minor physical harm will be viewed as normal more often than fights resulting in major physical harm).

Table 1.2 compares the amount of fights viewed as disturbing and the level of physical harm resulting from the fights. According to table 1.2, $42 \%$ of fights with major physical harm were viewed as disturbing compared to $23 \%$ of fights with minor harm. This figure is statistically significant $(\mathrm{p}=.013)$, therefore we accept hypothesis H1b (fights resulting in major physical harm will be viewed as disturbing more often than fights resulting in minor physical harm).

\footnotetext{
${ }^{3}$ Table percentages rounded to the nearest whole number.
} 
Table 1.1:

Normal Fights by Physical Harm

\begin{tabular}{ccc}
\hline Normal Fights & \multicolumn{2}{c}{ Physical Harm } \\
& Minor Harm & Major Harm \\
\hline \multirow{2}{*}{ Normal/No Effect } & 39 & 17 \\
& $(40 \%)$ & $(34.0 \%)$ \\
All Other Responses & 58 & 33 \\
& $(60 \%)$ & $(66.0 \%)$ \\
\hline \multirow{2}{*}{ Total } & $\mathbf{9 7}$ & $\mathbf{5 0}$ \\
& $\mathbf{( 1 0 0 \% )}$ & $\mathbf{( 1 0 0 \% )}$ \\
\hline
\end{tabular}

Note: $\chi^{2}=.539 ; \mathrm{p}=.291$

Table 1.2:

Disturbing Fights by Physical Harm

Disturbing Fights

\begin{tabular}{ccc} 
& Minor Harm & Major Harm \\
\hline Disturbing & 22 & 21 \\
& $(23 \%)$ & $(42 \%)$ \\
All Other Responses & 75 & 29 \\
Total & $(77 \%)$ & $(58 \%)$ \\
\hline \multirow{2}{*}{ To7 } & $\mathbf{5 0}$ \\
& $\mathbf{( 1 0 0 \% )}$ & $\mathbf{( 1 0 0 \% )}$ \\
\hline
\end{tabular}

Note: $\chi^{2}=5.950 ; p=.013$

\section{Violence Becomes Normal Over Time}

Table 2.1 compares the amount of fights viewed as normal and the age of the observer who reported the fight. According to table 2.1, 47\% of fights with an observer 21 years old or older were viewed as normal compared to $27 \%$ of fights with an observer under 21 years old. This figure is statistically significant $(\mathrm{p}=.011)$, therefore we accept hypothesis H2a (older students will view fights as normal more often than younger students).

Table 2.2 compares the amount of fights viewed as disturbing and the age of the observer who reported the fight. According to table 2.2, 30\% of fights with an observer 21 years or older were viewed as disturbing compared to $26 \%$ of fights with an observer under 21 years old. This 
figure is not statistically significant ( $\mathrm{p}=.344$ ), therefore we reject hypothesis $\mathrm{H} 2 \mathrm{~b}$ (younger students will view fights as disturbing more often than older students).

Table 2.1:

Normal Fights by Observer's Age

Normal Fights

\begin{tabular}{ccc} 
& Under 21 Years & 21 Years \& Over \\
\hline \multirow{2}{*}{ Normal/No Effect } & 18 & 39 \\
& $(27 \%)$ & $(47 \%)$ \\
All Other Responses & 48 & 44 \\
& $(73 \%)$ & $(53 \%)$ \\
\hline \multirow{2}{*}{ Total } & $\mathbf{6 6}$ & $\mathbf{8 3}$ \\
& $\mathbf{( 1 0 0 \% )}$ & $\mathbf{( 1 0 0 \% )}$ \\
\hline
\end{tabular}

Note: $\chi^{2}=6.050 ; p=.011$

Table 2.2:

Disturbing Fights by Observer's Age

Disturbing Fights

\begin{tabular}{ccc} 
& Under 21 Years & 21 Years \& Over \\
\hline \multirow{2}{*}{ Disturbing } & 17 & 25 \\
& $(26 \%)$ & $(30 \%)$ \\
All Other Responses & 49 & 58 \\
& $(74 \%)$ & $(70 \%)$ \\
\hline \multirow{2}{*}{ Total } & $\mathbf{6 6}$ & $\mathbf{8 3}$ \\
& $(\mathbf{1 0 0 \% )}$ & $\mathbf{( 1 0 0 \% )}$ \\
\hline
\end{tabular}

Note: $\chi^{2}=.346 ; p=.344$

Violence is Normal for Men, Non-Normal for Women

Table 3.1 compares the amount of fights viewed as normal and the sex of the fighters involved in the fights. According to table 3.1,39\% of fights with only male participants were viewed as normal compared to $33 \%$ of fights with only female participants. This figure is not statistically significant $(\mathrm{p}=.425)$, therefore we reject hypothesis $\mathrm{H3a}$ (fights with only male participants will be viewed as normal more often than fights involving only female participants). 
Table 3.2 compares the amount of fights viewed as disturbing and the sex of the fighters involved in the fights. According to table 3.2, $44 \%$ of fights with only female participants were viewed as disturbing compared to $28 \%$ of fights with only male participants. This figure is not statistically significant $(\mathrm{p}=.120)$, therefore we reject hypothesis H3b (fights with only female participants involved will be viewed as disturbing more often than fights involving only male participants).

Table 3.1:

Normal Fights by Fighter's Sex

Normal Fights

\begin{tabular}{ccc} 
& Female vs. Female & Male vs. Male \\
\hline \multirow{2}{*}{ Normal/No Effect } & 6 & 48 \\
& $(33 \%)$ & $(39 \%)$ \\
All Other Responses & 12 & 75 \\
& $(67 \%)$ & $(61 \%)$ \\
\hline Total & $\mathbf{1 8}$ & $\mathbf{1 2 3}$ \\
& $(\mathbf{1 0 0 \% )}$ & $\mathbf{( 1 0 0 \% )}$ \\
\hline
\end{tabular}

Fighter's Sex

Note: $\chi^{2}=.215 ; p=.425$ 
significant $(\mathrm{p}=.000)$, therefore we accept hypothesis H4a (male observers will view fights as normal more often than female observers).

Table 3.4 compares the amount of fights viewed as disturbing and the sex of the observer who reported the fight. According to table 3.4, 47\% of fights with a female observer were viewed as disturbing compared to $10 \%$ of fights with a male observer. This figure is statistically significant $(\mathrm{p}=.000)$, therefore we accept hypothesis H4b (female observers will view fights as disturbing more often than male observers).

Table 3.3:

Normal Fights by Observer's Sex

\begin{tabular}{ccc}
\hline Normal Fights & \multicolumn{2}{c}{ Observer's Sex } \\
& Female & Male \\
\hline \multirow{2}{*}{ Normal/No Effect } & 17 & 40 \\
& $(23 \%)$ & $(53 \%)$ \\
All Other Responses & 57 & 36 \\
& $(77 \%)$ & $(47 \%)$ \\
\hline \multirow{2}{*}{ Total } & $\mathbf{7 4}$ & $\mathbf{7 6}$ \\
& $\mathbf{( 1 0 0 \% )}$ & $\mathbf{( 1 0 0 \% )}$ \\
\hline
\end{tabular}

Note: $\chi^{2}=13.998 ; p=.000$

\section{Table 3.4:}

Disturbing Fights by Observer's Sex

\section{Disturbing Fights}

\begin{tabular}{cc} 
& Female \\
\hline & 35 \\
Disturbing & $(47 \%)$
\end{tabular}

Disturbing

All Other Responses

Total

Note: $\chi^{2}=24.791 ; p=.000$

\section{Observer's Sex}

Male

8

39

$(53 \%)$

74

$(100 \%)$
$(10 \%)$

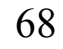

$(90 \%)$

76

$(100 \%)$ 


\section{Normality of Violence is Situational}

Table 4.1 compares the amount of fights viewed as normal and the specific trigger responsible for starting the fight. According to table 4.1, 50\% of fights that occurred over romantic relationships were viewed as normal compared to $50 \%$ of fights that occurred over minor physical harms, $34 \%$ of fights that occurred over individual/social identity, and $32 \%$ of fights that occurred over an attempt to gain status. This figure is not statistically significant $(\mathrm{p}=$ .391), thus situational triggers have no indication on the normality of fights.

Table 4.2 compares the amount of fights viewed as disturbing and the specific trigger primarily responsible for starting the fight. According to table 4.2, 36\% of fights that occurred over romantic relationships were viewed as disturbing compared to $28 \%$ of fights that occurred over individual/social identity, $26 \%$ of fights that occurred due to an attempt to gain status, and $15 \%$ of fights that occurred over minor physical harms. This figure is not statistically significant $(p=.507)$, thus situational triggers also have no indication on fights seen as disturbing.

\section{Table 4.1:}

Normal Fights by Situational Trigger

\begin{tabular}{ccccc}
$\begin{array}{c}\text { Normal } \\
\text { Fights }\end{array}$ & $\begin{array}{c}\text { Minor } \\
\text { Physical } \\
\text { Harms }\end{array}$ & $\begin{array}{c}\text { Status } \\
\text { Gain }\end{array}$ & $\begin{array}{c}\text { Situational Trigger } \\
\text { Romantic } \\
\text { Relationships }\end{array}$ & $\begin{array}{c}\text { Individual/Social } \\
\text { Identity }\end{array}$ \\
\hline $\begin{array}{c}\text { Normal/No } \\
\text { Effect }\end{array}$ & 13 & 6 & 7 & 21 \\
& $(50 \%)$ & $(32 \%)$ & $(50 \%)$ & $(34 \%)$ \\
\hline $\begin{array}{c}\text { All Other } \\
\text { Responses }\end{array}$ & 13 & 13 & 7 & 40 \\
\hline Total & $(50 \%)$ & $(68 \%)$ & $(50 \%)$ & $(66 \%)$ \\
\hline
\end{tabular}

Note: $\chi^{2}=3.005 ; \mathrm{p}=.391$ 


\begin{tabular}{|c|c|c|c|c|}
\hline \multicolumn{5}{|c|}{$\begin{array}{c}\text { Table 4.2: } \\
\text { Disturbing Fights by Situational Trigger }\end{array}$} \\
\hline \multirow{2}{*}{$\begin{array}{l}\text { Disturbing } \\
\text { Fights }\end{array}$} & \multicolumn{4}{|c|}{ Situational Trigger } \\
\hline & $\begin{array}{c}\text { Minor } \\
\text { Physical } \\
\text { Harms }\end{array}$ & $\begin{array}{l}\text { Status } \\
\text { Gain }\end{array}$ & $\begin{array}{c}\text { Romantic } \\
\text { Relationships }\end{array}$ & $\begin{array}{l}\text { Individual/Social } \\
\text { Identity }\end{array}$ \\
\hline Disturbing & $\begin{array}{c}4 \\
(15 \%)\end{array}$ & $\begin{array}{c}5 \\
(26 \%)\end{array}$ & $\begin{array}{c}5 \\
(36 \%)\end{array}$ & $\begin{array}{c}17 \\
(28 \%)\end{array}$ \\
\hline $\begin{array}{l}\text { All Other } \\
\text { Responses }\end{array}$ & $\begin{array}{c}22 \\
(85 \%)\end{array}$ & $\begin{array}{c}14 \\
(74 \%)\end{array}$ & $\begin{array}{c}9 \\
(64 \%)\end{array}$ & $\begin{array}{c}44 \\
(72 \%)\end{array}$ \\
\hline Total & $\begin{array}{c}26 \\
(100 \%)\end{array}$ & $\begin{array}{c}19 \\
(100 \%)\end{array}$ & $\begin{array}{c}14 \\
(100 \%)\end{array}$ & $\begin{array}{c}61 \\
(100 \%)\end{array}$ \\
\hline
\end{tabular}

Note: $\chi^{2}=2.329 ; p=.507$

Table 4.3 compares the amount of fights viewed as normal and the level of intoxication of both sides of the fighters. According to table 4.3, $40 \%$ of fights with all sides intoxicated were viewed as normal compared to $36 \%$ of fights with one side intoxicated and $32 \%$ with no sides intoxicated. This figure is not statistically significant $(\mathrm{p}=.782)$, thus a fighter's intoxication has no indication on the normality of fights.

Table $4.4^{4}$ compares the amount of fights viewed as disturbing and the level of intoxication of both sides of the fighters. According to table 4.4,30\% of fights with all sides intoxicated were viewed as disturbing compared to $27 \%$ of fights with no sides intoxicated and $21 \%$ with one side intoxicated. This figure is not statistically significant $(\mathrm{p}=.797)$, thus a fighter's intoxication has no indication on fights seen as disturbing.

\footnotetext{
${ }^{4}$ Fisher's Exact Test used due to number of units less than 5.
} 
Table 4.3:

Normal Fights by Fighter's Intoxication

\begin{tabular}{cccc} 
Normal Fights & None/Low & $\begin{array}{c}\text { Fighter's Intoxication } \\
\text { One Side } \\
\text { Intoxicated }\end{array}$ & $\begin{array}{c}\text { All Sides } \\
\text { Intoxicated }\end{array}$ \\
\hline Normal/No Effect & 7 & 5 & 45 \\
All Other & $152 \%)$ & $(36 \%)$ & $(40 \%)$ \\
Responses & $(68 \%)$ & 9 & 69 \\
Total & $\mathbf{2 2}$ & $(64 \%)$ & $(60 \%)$ \\
\hline
\end{tabular}

Note: $\chi^{2}=.493 ; p=.782$

\section{Table 4.4:}

Disturbing Fights by Fighter's Intoxication

\begin{tabular}{cccc} 
Disturbing Fights & None/Low & $\begin{array}{c}\text { Fighter's Intoxication } \\
\text { One Side } \\
\text { Intoxicated }\end{array}$ & $\begin{array}{c}\text { All Sides } \\
\text { Intoxicated }\end{array}$ \\
\hline Disturbing & 6 & 3 & 34 \\
All Other & $(27 \%)$ & $(21 \%)$ & $(30 \%)$ \\
Responses & $(73 \%)$ & 11 & 80 \\
Total & $\mathbf{2 2}$ & $(79 \%)$ & $(70 \%)$ \\
\hline & $(\mathbf{1 0 0 \% )}$ & $\mathbf{1 4}$ & $\mathbf{1 1 4}$ \\
& & $(\mathbf{1 0 0 \% )}$ & $\mathbf{( 1 0 0 \% )}$ \\
\hline
\end{tabular}

Note: $\chi^{2}=.454 ; p=.797$

Table 4.5 compares the amount of fights viewed as normal and the day in which the fight occurred. According to table 4.5, 41\% of fights that occurred on the weekend were viewed as normal compared to $28 \%$ of fights that occurred during school days. This figure is not statistically significant $(p=.100)$, thus the day in which a fight occurs has no indication on the normality of fights.

Table 4.6 compares the amount of fights viewed as disturbing and the day in which the fight occurred. According to table 4.6, 30\% of fights that occurred on the weekend were viewed as disturbing compared to $26 \%$ of fights that occurred during school days. This figure is not statistically significant $(\mathrm{p}=.395)$, thus the day in which a fight occurs has no indication on fights seen as disturbing. 


\begin{tabular}{ccc}
\hline \multicolumn{3}{c|}{ Table 4.5: } \\
Normal Fights by Day \\
\hline Normal Fights & \multicolumn{2}{c}{ Day } \\
& School Days (Mon-Thurs) & Weekend Days (Fri-Sun) \\
\hline \multirow{2}{*}{ Normal/No Effect } & 11 & 46 \\
& $(28 \%)$ & $(41 \%)$ \\
All Other Responses & 28 & 65 \\
& $(72 \%)$ & $(59 \%)$ \\
\hline \multirow{2}{*}{ Total } & $\mathbf{3 9}$ & $\mathbf{1 1 1}$ \\
& $(\mathbf{1 0 0 \% )}$ & $\mathbf{( 1 0 0 \% )}$ \\
\hline
\end{tabular}

Note: $\chi^{2}=2.146 ; p=.100$

\begin{tabular}{ccc}
\hline & Table 4.6: \\
& \multicolumn{2}{c|}{ Disturbing Fights by Day } \\
\hline Disturbing Fights & \multicolumn{2}{c}{ Day } \\
& School Days (Mon-Thurs) & Weekend Days (Fri-Sun) \\
\hline \multirow{2}{*}{ Disturbing } & 10 & 33 \\
& $(26 \%)$ & $(30 \%)$ \\
All Other Responses & 29 & 78 \\
& $(74 \%)$ & $(70 \%)$ \\
\hline \multirow{2}{*}{ Total } & $\mathbf{3 9}$ & $\mathbf{1 1 1}$ \\
& $(\mathbf{1 0 0 \% )}$ & $\mathbf{( 1 0 0 \% )}$ \\
\hline
\end{tabular}

Note: $\chi^{2}=.236 ; \mathrm{p}=.395$

Table 4.7 compares the amount of fights viewed as normal and the time of day in which the fight occurred. According to table 4.7, 40\% of fights that occurred at nighttime were viewed as normal compared to $26 \%$ of fights that occurred during the daytime. This figure is not statistically significant $(p=.148)$, thus the time in which a fight occurs has no indication on the normality of fights.

Table 4.8 compares the amount of fights viewed as disturbing and the time of day in which the fight occurred. According to table 4.8, 30\% of fights that occurred during the daytime were viewed as disturbing compared to $28 \%$ of fights that occurred during the nighttime. This figure is not statistically significant $(\mathrm{p}=.508)$, thus the time in which a fight occurs has no indication on fights seen as disturbing. 


\begin{tabular}{|c|c|c|}
\hline \multicolumn{3}{|c|}{$\begin{array}{c}\text { Table 4.7: } \\
\text { Normal Fights by Time }\end{array}$} \\
\hline \multirow[t]{2}{*}{ Normal Fights } & \multicolumn{2}{|c|}{ Time } \\
\hline & Daytime & Nighttime \\
\hline Normal/No Effect & $\begin{array}{c}6 \\
(26 \%)\end{array}$ & $\begin{array}{c}51 \\
(40 \%)\end{array}$ \\
\hline All Other Responses & $\begin{array}{c}17 \\
(74 \%)\end{array}$ & $\begin{array}{c}76 \\
(60 \%)\end{array}$ \\
\hline Total & $\begin{array}{c}23 \\
(100 \%)\end{array}$ & $\begin{array}{c}127 \\
(100 \%)\end{array}$ \\
\hline
\end{tabular}

Note: $\chi^{2}=1.636 ; p=.148$

\section{Table 4.8:}

Disturbing Fights by Time

Disturbing Fights

\begin{tabular}{ccc} 
& Daytime & Nighttime \\
\hline \multirow{2}{*}{ Disturbing } & 7 & 36 \\
& $(30 \%)$ & $(28 \%)$ \\
All Other Responses & 16 & 91 \\
& $(70 \%)$ & $(72 \%)$ \\
\hline Total & $\mathbf{2 3}$ & $\mathbf{1 2 7}$ \\
& $\mathbf{( 1 0 0 \% )}$ & $\mathbf{( 1 0 0 \% )}$ \\
\hline
\end{tabular}

Note: $\chi^{2}=.042 ; p=.508$

Table 4.9 compares the amount of fights viewed as normal and the number of bystanders who witnessed the fight. According to table 4.9, 46\% of fights with a few bystanders present were viewed as normal compared to $42 \%$ of fights with a small crowd present and $33 \%$ of fights with a large crowd present. This figure is not statistically significant $(\mathrm{p}=.371)$, thus the number of bystanders witnessing the fight has no indication on the normality of fights.

Table 4.10 compares the amount of fights viewed as disturbing and the number of bystanders who witnessed the fight. According to table 4.10,33\% of fights with a large crowd present were viewed as disturbing compared to $29 \%$ of fights with a small crowd and $17 \%$ of fights with a few bystanders present. This figure is not statistically significant $(p=.221)$, thus the number of bystanders witnessing the fight has no indication on fights seen as disturbing. 
Table 4.9:

Normal Fights by Crowd Composition

Normal Fights

\section{Few (1-5)}

\section{Number of Bystanders}

Large Crowd (11+)

\begin{tabular}{cccc}
\hline Normal/No Effect & 16 & 13 & 27 \\
& $(46 \%)$ & $(42 \%)$ & $(33 \%)$ \\
All Other Responses & 19 & 18 & 55 \\
& $(54 \%)$ & $(58 \%)$ & $(67 \%)$ \\
\hline Total & $\mathbf{3 5}$ & $\mathbf{3 1}$ & $\mathbf{8 2}$ \\
& $\mathbf{( 1 0 0 \% )}$ & $\mathbf{( 1 0 0 \% )}$ & $\mathbf{( 1 0 0 \% )}$ \\
\hline
\end{tabular}

Note: $\chi^{2}=1.985 ; p=.371$

\section{Table 4.10:}

Disturbing Fights by Crowd Composition

Disturbing Fights

\begin{tabular}{cccc} 
Disturbing Fights & \multicolumn{3}{c}{ Number of Bystanders } \\
& Few (1-5) & Small Crowd (6-10) & Large Crowd (11+) \\
\hline Disturbing & 6 & 9 & 27 \\
& $(17 \%)$ & $(29 \%)$ & $(33 \%)$ \\
All Other Responses & 29 & 22 & 55 \\
& $(83 \%)$ & $(71 \%)$ & $(67 \%)$ \\
\hline Total & $\mathbf{3 5}$ & $\mathbf{3 1}$ & $\mathbf{8 2}$ \\
& $(\mathbf{1 0 0 \% )}$ & $\mathbf{( 1 0 0 \% )}$ & $\mathbf{( 1 0 0 \% )}$
\end{tabular}

Note: $\chi^{2}=3.015 ; p=.221$

Table $4.11^{5}$ compares the amount of fights viewed as normal and the race of the fighters involved. According to table 4.11, 47\% of fights with white vs. other minority participants were viewed as normal compared to $36 \%$ of fights with white vs. white participants. This figure is not statistically significant $(\mathrm{p}=.214)$, thus the race of the fighters has no indication on the normality of fights.

\footnotetext{
${ }^{5}$ Due to small number of cases (less than 5), fights involving only black individuals were excluded from analysis.
} 
Table 4.12 compares the amount of fights viewed as disturbing and the race of the fighters involved. According to table 4.12, $29 \%$ of fights with white vs. white participants were viewed as disturbing compared to $23 \%$ of fights with white vs. other minorities. This figure is not statistically significant $(\mathrm{p}=.365)$, thus the race of the fighters has no indication on fights seen as disturbing.

\begin{tabular}{ccc}
\hline & \multicolumn{2}{c|}{ Table 4.11: } \\
& \multicolumn{2}{c}{ Normal Fights by Fighter's Race } \\
\hline Normal Fights & \multicolumn{2}{c}{ Fighter's Race } \\
& White vs. White & White vs. Other Minorities \\
\hline \multirow{2}{*}{ Normal/No Effect } & 38 & 14 \\
& $(36 \%)$ & $(47 \%)$ \\
All Other Responses & 66 & 16 \\
& $(64 \%)$ & $(53 \%)$ \\
\hline Total & $\mathbf{1 0 4}$ & $\mathbf{3 0}$ \\
& $(\mathbf{1 0 0 \% )}$ & $(\mathbf{1 0 0 \% )}$ \\
\hline
\end{tabular}

Note: $\chi^{2}=1.006 ; p=.214$

\section{Table 4.12:}

Disturbing Fights by Fighter's Race

\section{Disturbing Fights}

$\frac{\text { White vs. White }}{30}$

Disturbing

\begin{tabular}{ccc} 
All Other Responses & 74 & 23 \\
& $(71 \%)$ & $(77 \%)$ \\
\hline \multirow{2}{*}{ Total } & $\mathbf{1 0 4}$ & $\mathbf{3 0}$ \\
& $(\mathbf{1 0 0 \% )}$ & $\mathbf{( 1 0 0 \% )}$ \\
\hline
\end{tabular}

Fighter's Race

White vs. Other Minorities

$(29 \%)$

$(23 \%)$

$(\mathbf{1 0 0 \%})$

Note: $\chi^{2}=.345 ; p=.365$

Table 4.13 compares the amount of fights viewed as normal and the stature (body size) of the fighters involved. According to table $4.13,43 \%$ of fights with fighters of similar stature were viewed as normal compared to $30 \%$ of fights with fighters of different statures. This figure is not 
statistically significant $(p=.167)$, thus the stature of the fighters has no indication on the normality of fights.

Table 4.14 compares the amount of fights viewed as disturbing and the stature (body size) of the fighters involved. According to table 4.14, 37\% of fights with fighters of different statures were viewed as disturbing compared to $29 \%$ of fights with fighters of similar stature. This figure is not statistically significant $(\mathrm{p}=.310)$, thus the stature of the fighters has no indication on fights seen as disturbing.

\begin{tabular}{ccc}
\hline \multicolumn{3}{c|}{ Table 4.13: } \\
Normal Fights by Fighter's Stature \\
\hline \multirow{2}{*}{ Fighter's Stature } \\
& \multicolumn{3}{c|}{ Symmetrical } & Asymmetrical \\
\hline \multirow{2}{*}{ Normal/No Effect } & 28 & 8 \\
& $(43 \%)$ & $(30 \%)$ \\
All Other Responses & 37 & 19 \\
& $(57 \%)$ & $(70 \%)$ \\
\hline \multirow{2}{*}{ Total } & $\mathbf{6 5}$ & $\mathbf{2 7}$ \\
& $(\mathbf{1 0 0 \% )}$ & $\mathbf{( 1 0 0 \% )}$ \\
\hline
\end{tabular}

Note: $\chi^{2}=1.448 ; p=.167$

Table 4.14:

Disturbing Fights by Fighter's Stature

\begin{tabular}{ccc}
\hline Disturbing Fights & \multicolumn{2}{c}{ Fighter's Stature } \\
& Symmetrical & Asymmetrical \\
\hline \multirow{2}{*}{ Disturbing } & 19 & 10 \\
& $(29 \%)$ & $(37 \%)$ \\
All Other Responses & 46 & 17 \\
& $(71 \%)$ & $(63 \%)$ \\
\hline \multirow{2}{*}{ Total } & $\mathbf{6 5}$ & $\mathbf{2 7}$ \\
& $\mathbf{( 1 0 0 \% )}$ & $\mathbf{( 1 0 0 \% )}$ \\
\hline
\end{tabular}

Note: $\chi^{2}=.539 ; \mathrm{p}=.310$

Table 4.15 compares the amount of fights viewed as normal and the willingness of the fighters involved. According to table $4.15,43 \%$ of fights with fighters who have a similar 
willingness to fight were viewed as normal compared to $27 \%$ of fights with fighters who have a different willingness to fight. This figure is statistically significant $(p=.047)$, indicating that fights are seen as normal more often when the fighters' desire to fight is similar.

Table 4.16 compares the amount of fights viewed as disturbing and the willingness of the fighters involved. According to table 4.16, 35\% of fights with fighters who have a different willingness to fight were viewed as disturbing compared to $24 \%$ of fights with fighters who have a similar willingness to fight. This figure is not statistically significant $(p=.119)$, thus the willingness of the fighters has no indication on fights seen as disturbing.

Table 4.15:

Normal Fights by Fighter's Willingness to Fight

Normal Fights

Fighter's Willingness to Fight

\begin{tabular}{ccc} 
& Symmetrical & Asymmetrical \\
\hline \multirow{2}{*}{ Normal/No Effect } & 42 & 13 \\
& $(43 \%)$ & $(27 \%)$ \\
All Other Responses & 56 & 35 \\
Total & $(57 \%)$ & $(73 \%)$ \\
\hline \multirow{2}{*}{ (100\%) } & $\mathbf{4 8}$ \\
& $\mathbf{( 1 0 0 \% )}$ \\
\hline
\end{tabular}

Note: $\chi^{2}=3.414 ; p=.047$

\section{Table 4.16:}

Disturbing Fights by Fighter's Willingness to Fight

Disturbing Fights

Fighter's Willingness to Fight Symmetrical Asymmetrical

\begin{tabular}{ccc}
\hline Disturbing & 24 & 17 \\
& $(24 \%)$ & $(35 \%)$ \\
All Other Responses & 74 & 31 \\
& $(76 \%)$ & $(65 \%)$ \\
\hline \multirow{2}{*}{ Total } & $\mathbf{9 8}$ & $\mathbf{4 8}$ \\
& $\mathbf{( 1 0 0 \% )}$ & $\mathbf{( 1 0 0 \% )}$ \\
\hline
\end{tabular}

Note: $\chi^{2}=1.905 ; p=.119$ 
Table 4.17 compares the amount of fights viewed as normal and the number of fighters on each side. According to table $4.17,42 \%$ of fights with an equal amount of fighters on each side were viewed as normal compared to $22 \%$ of fights with an unequal amount of fighters on each side. This figure is statistically significant $(\mathrm{p}=.044)$, indicating that fights are seen as normal more often when each side had an equal amount of fighters.

Table 4.18 compares the amount of fights viewed as disturbing and the number of fighters on each side. According to table 4.18, 37\% of fights with an unequal amount of fighters on each side were viewed as disturbing compared to $27 \%$ of fights with an equal amount of fighters on each side. This figure is not statistically significant $(p=.209)$, thus the number of fighters on each side has no indication on fights seen as disturbing.

\section{Table 4.17:}

Normal Fights by Number of Fighters

Normal Fights

\begin{tabular}{ccc} 
& Symmetrical & Asymmetrical \\
Normal/No Effect & 51 & 6 \\
& $(42 \%)$ & $(22 \%)$ \\
All Other Responses & 71 & 21 \\
Total & $(58 \%)$ & $(78 \%)$ \\
\hline \multirow{2}{*}{ Toto } & $\mathbf{1 2 2}$ & $\mathbf{2 7}$ \\
& $\mathbf{( 1 0 0 \% )}$ & $\mathbf{( 1 0 0 \% )}$ \\
\hline
\end{tabular}

\section{Number of Fighters} Symmetrical
Note: $\chi^{2}=3.589 ; p=.044$

Table 4.18:

Disturbing Fights by Fighter's Number of Fighters

\section{Disturbing Fights}

\begin{tabular}{ccc} 
& Symmetrical & Asymmetrical \\
\hline \multirow{2}{*}{ Disturbing } & 33 & 10 \\
& $(27 \%)$ & $(37 \%)$ \\
All Other Responses & 89 & 17 \\
& $(73 \%)$ & $(63 \%)$ \\
\hline \multirow{2}{*}{ Total } & $\mathbf{1 2 2}$ & $\mathbf{2 7}$ \\
& $\mathbf{( 1 0 0 \% )}$ & $\mathbf{( 1 0 0 \% )}$ \\
\hline
\end{tabular}

umber of Fighters

Note: $\chi^{2}=1.074 ; p=.209$ 
Table 4.19 compares the amount of fights viewed as normal and the observer's perceived planning of the fight. According to table 4.19, 55\% of fights perceived as planned or in retaliation were viewed as normal compared to $34 \%$ of fights perceived as unplanned or spontaneous. This figure is statistically significant $(\mathrm{p}=.030)$, indicating that fights are seen as normal more often when they are planned or in retaliation to a previous offense.

Table 4.20 compares the amount of fights viewed as disturbing and the observer's perceived planning of the fight. According to table 4.20, $28 \%$ of fights perceived as unplanned or spontaneous were viewed as disturbing compared to $19 \%$ of fights perceived as planned or in retaliation. This figure is not statistically significant $(p=.254)$, thus the perceived planning of the fight has no indication on fights seen as disturbing.

\section{Table 4.19:}

Normal Fights by Perceived Planning of Fight

\begin{tabular}{ccc}
\hline Normal Fights & $\begin{array}{c}\text { Planning } \\
\text { Unplanned/Spontaneous }\end{array}$ & Planned/Retaliation \\
\hline \multirow{2}{*}{ Normal/No Effect } & 33 & 17 \\
& $(34 \%)$ & $(55 \%)$ \\
All Other Responses & 65 & 14 \\
& $(66 \%)$ & $(45 \%)$ \\
\hline Total & $\mathbf{9 8}$ & $\mathbf{3 1}$ \\
& $\mathbf{( 1 0 0 \% )}$ & $\mathbf{( 1 0 0 \% )}$ \\
\hline
\end{tabular}

Note: $\chi^{2}=4.445 ; p=.030$

\section{Table 4.20:}

Disturbing Fights Perceived Planning of Fight

\begin{tabular}{ccc} 
Disturbing Fights & \multicolumn{2}{c}{ Planning } \\
& Unplanned/Spontaneous & Planned/Retaliation \\
\hline \multirow{2}{*}{ Disturbing } & 27 & 6 \\
& $(28 \%)$ & $(19 \%)$ \\
All Other Responses & 71 & 25 \\
& $(72 \%)$ & $(81 \%)$ \\
\hline \multirow{2}{*}{ Total } & $\mathbf{9 8}$ & $\mathbf{3 1}$ \\
& $\mathbf{( 1 0 0 \% )}$ & $\mathbf{( 1 0 0 \% )}$ \\
\hline
\end{tabular}

Note: $\chi^{2}=.831 ; \mathrm{p}=.254$ 
Table 4.21 compares the amount of fights viewed as normal and the observer's perceived fairness of the fight. According to table 4.21, 46\% of fights perceived as fair were viewed as normal compared to $18 \%$ of fights perceived as unfair. This figure is statistically significant $(\mathrm{p}=$ .001 ), indicating that fights are seen as normal more often when they are considered by the observer to be fair.

Table 4.22 compares the amount of fights viewed as disturbing and the observer's perceived planning of the fight. According to table 4.22, 48\% of fights perceived as unfair were viewed as disturbing compared to $21 \%$ of fights perceived as fair. This figure is statistically significant $(\mathrm{p}=.001)$, indicating that fights are seen as disturbing more often they are considered by the observer to be unfair.

Table 4.21:

Normal Fights by Fairness of Fight

\begin{tabular}{ccc}
\hline Normal Fights & Fair & Unfair \\
\hline \multirow{2}{*}{ Normal/No Effect } & 48 & 8 \\
& $(46 \%)$ & $(18 \%)$ \\
All Other Responses & 57 & 36 \\
Total & $(54 \%)$ & $(82 \%)$ \\
\hline \multirow{2}{*}{ To5 } & $\mathbf{4 4}$ \\
& $\mathbf{1 0 5}$ & $\mathbf{( 1 0 0 \% )}$ \\
\hline
\end{tabular}

Note: $\chi^{2}=10.020 ; p=.001$

\section{Table 4.22:}

Disturbing Fights by Fairness of Fight

\begin{tabular}{ccc}
\hline Disturbing Fights & Fair & Unfair \\
\hline \multirow{2}{*}{ Disturbing } & 22 & 21 \\
& $(21 \%)$ & $(48 \%)$ \\
All Other Responses & 83 & 23 \\
& & $(52 \%)$ \\
\hline \multirow{2}{*}{ Total } & $(79 \%)$ & $\mathbf{4 4}$ \\
& $\mathbf{1 0 5}$ & $(\mathbf{1 0 0 \% )}$ \\
\hline
\end{tabular}

Note: $\chi^{2}=10.827 ; p=.001$ 
After comparing the normality of fights to situational characteristics, we have concluded:

- We must reject hypothesis H5a (fights with situational characteristics related to the college subculture and fair fighting will be viewed as normal more often than disturbing is proven false).

- We must reject hypothesis H5b (fights with situational characteristics not related to the college subculture and unfair fighting will be viewed as disturbing more often than normal is proven false).

\section{DISCUSSION}

This study is exploratory in nature, with our main goals being to describe the situational characteristics of college fighting and demonstrate whether these variables are meaningful predictors of people's reactions to it, controlling for the following trait-based variables: the severity of harm dealt to the fighters, the age of the participant observers, the gender of the fighters as well as the participant observers, and situational characteristics related to the college nighttime culture and composition of the fights.

\section{Norms Against the Use of Violence}

Our first argument is that while crime and violence are inevitable norms in societies today, norms against the use of interpersonal violence exist under certain circumstances. More specifically, due to the societal decrease in frequency and severity of violence (Durkheim 1982; Pinker 2011), we argue that fights transition from normal to abnormal once the acceptable level of violence has been surpassed.

Results of the analysis indicate that the severity of injury sustained from a fight is an adequate predictor in determining if a fight will be viewed as disturbing. The results support the idea written by Emile Durkheim (1982): once injuries escalate to a more severe form, a line deemed acceptable by society is crossed and violence is no longer normal.

Results of the analysis does not support our argument that the severity of injury sustained is an adequate predictor in determining if a fight will be viewed as normal. The results are not statistically significant; they do show a pattern between severity of injury and the normality of fighting. If a larger sample size is obtained, the results may become statistically significant. 


\section{Violence Becomes Normal Over Time}

The second argument we make is that violence is not perceived as normal at first, but becomes normal over time. More specifically, as students grow older, they become accustomed to the party subculture of their college. Therefore, acts associated with this subculture become normalized. This assertion is a direct reference to Huesmann and Guerra (1997), who state: "both normative beliefs approving of aggression and actual aggressive behavior increase with age."

Results of the analysis indicate that the age of the observer is an adequate predictor in determining if a fight will be viewed as normal. The normal fight analysis supports the assertion that as we get older, we form normative beliefs pertaining to acts of aggression (Huesmann and Guerra 1997) and that these normative beliefs can be created in a short period of time (Fanti 2009).

The disturbing fight analysis yielded interesting results. I expected not only younger students to view fights as disturbing more often than older students, but for that number to be highly significant. One possibility for these results could be that the opportunity for younger students to see fights is not as high as older students.

A majority of these fights occurred around activities associated with alcohol use, in which only individuals who are at least twenty-one years old can purchase. Due to this limitation for younger students, there may not be as many students present in the high party areas, thus lessoning the overall number of fights witnessed by younger students.

The above statement can be explained with the social learning process described by Albert Bandura. Bandura (1971) states that in order for an individual to experience new patterns of behavior, they need have the ability to be able to experience these patterns. If younger students are limited in their ability to partake in a large number of weekend activities where these fights occur, the overall number of experiences for younger students will be lower. Therefore, the results on fights viewed as disturbing may be skewed in favor of the older students since the younger students are not out experiencing the fights taking place.

\section{Violence is Normal for Men, Non-Normal for Women}

The third argument we make is that violence is normal for men, but not for women. More specifically, gender socialization in early life produces more acceptance of violence among men 
than women as well as women have a stronger emotional reaction to violence than men. These arguments directly relate to research conducted by Stark (2007) and Lowe et al. (2012).

The first theme of this argument compares the sex of the fighters involved. Results indicate that the sex of the fighters is not an adequate predictor in determining if a fight will be viewed as normal or disturbing. However, patterns do show a positive correlation between the variables. If a larger sample size is obtained, the results may become statistically significant.

When viewing fights involving women, many of the observers felt entertained. Since this emotion is not grouped as either normal or disturbing, the statistical significance of the results is affected. When comparing the sex of the fighters, the categorization 'other' in the Psychological Harm variable needs to be addressed and accounted for.

The second theme of this argument compares the sex of the observers. Results indicate that the sex of the observers is an adequate predictor in determining if a fight will be viewed as normal or disturbing. The analysis supports the idea that fighting is more upsetting to female witnesses (Lowe et al. 2012) as well as females are generally more empathic or sympathetic than males (Hoffman 1977; Feshbach 1982; Eagly and Crowley 1986), while men are less likely to show a strong emotional reaction.

\section{Normality of Violence is Situational}

The last argument we make is that violence is normal in some situations, but not in others. More specifically, we focus on situational characteristics related to the college party subculture (triggers and time context) and overall fight composition. This assertion is a direct reference to Rossow (1996) who states: "alcohol may facilitate violence when adolescents are drinking with friends in an unsupervised setting" and when the use of alcohol is involved, it leads to misbehavior in cultures where alcohol is viewed as a form of "time out," i.e., where the normal rules of interaction are relaxed (McAndrew and Edgerton 1969).

The first theme of this argument compares situational characteristics pertaining to the time/day, triggers, and intoxication levels related to the college subculture. Overall, results of the analysis indicate that the previously mentioned situational characteristics are not adequate predictors in determining if a fight will be viewed as normal or disturbing.

The results of this analysis are surprising. We predicted that fights would be viewed as disturbing when the situation of the fight was not associated with the college subculture, i.e. 
fights occurring on schooldays during the day with no sides intoxicated to yield the greatest numbers of disturbed fights. However the results of the analysis do not differ much with the analysis of normal fights.

Patterns of the analysis suggest that the situational characteristics related to the college subculture may influence normality of fighting. If a larger sample is obtained, these results may become statistically significant.

The second theme of this argument compares situational characteristics pertaining to the fight composition. Overall, results of the analysis indicate that situational characteristics related to the fight composition are not adequate predictors in determining if a fight will be viewed as normal or disturbing.

However, the observer's perceived fairness of the fight does play an important role. These results can be explained by applying the normality of violence described by Emile Durkheim. Fighting is deemed acceptable (or normal) if all sides are equal, but if one side has an unfair advantage over the other, fighting then becomes abnormal.

\section{CONCLUSION}

In conclusion, we set out to explore four theories that may explain the students' reactions to the violent incidents and recognize patterns that my show regularities in how violence is normalized on college campuses. We found that:

1) The severity of harm adequately predicts whether a fight is viewed as disturbing, but not normal.

2) While age adequately predicts that fights will be viewed as normal, age is not a valid predictor in assessing if a fight will be viewed as disturbing.

3) The sex of the observers is an adequate predictor in assessing if fights are viewed as normal or disturbing, but not the sex of the fighters.

4) Situational characteristics related to the college subculture and fight composition do not adequately predict if fights are viewed as normal or disturbing. 


\section{Limitations}

Due to the exploratory nature of this study, several limitations exist. This study is primarily limited by the size of its sample ( $\mathrm{n}=150)$. Many of the variables researched had relationships that supported the hypotheses, however, the distributions for these variables were not significant. Increasing the sample size in future research studies may give a more accurate significance. Lastly, we did not test whether each of the variables would hold true when controlling for all of the other variables.

Future studies need to use a larger sample and run a multiple regression analysis, which would allow them to control for every variable. 


\section{REFERENCES}

Allen, Mary and Catherine Devitt. 2012. "Intimate Partner Violence and Belief Systems in Liberia." Journal of Interpersonal Violence 27(17):3514-31.

Ambert, A. M., P. A. Adler, P. Adler, and D. F. Detzner. 1995. "Understanding and Evaluating Qualitative Research." Journal of Marriage and the Family 57:879-93.

Archer, John and Barbara Lloyd. 2002. Sex and Gender. Cambridge, UK: Cambridge University Press.

Austin, William. 1979. "Sex differences in Bystander Intervention in a Theft." Journal of Personality and Social Psychology 37(11):2110-20.

Babbie, Earl. 2008. The Basics of Social Research. Belmont, CA: Wadsworth (4th ed.).

Bandura, Albert. 1971. Social Learning Theory. New York, NY: General Learning Corporation.

Birkbeck, Christopher and Gary LaFree. 1993. "The Situational Analysis of Crime and Deviance." Annual Review of Sociology 19:113-37.

Bloom, G.A., and M. D. Smith. 1996. "Hockey Violence: A Test of the Cultural Spillover Theory." Sociology of Sport Journal 13:65-78.

Borell, Klas. 2008. "Terrorism and Everyday Life in Beirut 2005: Mental Reconstructions, Precautions and Normalization." Acta Sociologica 51(1):55-70.

Bushman, Brad J. and Harris M. Cooper. 1990. "Effects of Alcohol and Human Aggression: An Integrative Research Review." Psychological Bulletin 107:341-54.

Campbell, Anne. 1993. Men, Women, and Aggression. New York, NY: Basic Books.

Curry, Timothy Jon. 1993. "A Little Pain Never Hurt Anyone: Athletic Career Socialization and the Normalization of Sports Injury." Symbolic Interaction 16(3):273-90.

Day, Katy, Brendan Gough, and Majella McFadden. 2003. "Women Who Drink and Fight: A Discourse Analysis of Working Class Women's Talk." Feminism and Psychology 13:141-58.

Dunlap, Eloise, Andrew Golub, Bruce D. Johnson, and Ellen Benoit. 2009. "Normalization of Violence: Experiences of Childhood Abuse by Inner-City Crack Users." Journal of Ethnicity in Substance Abuse 8:15-34. 
Durkheim, Emile. 1982. The Rules of Sociological Method. (S. Lukes, Ed., W.D. Halls, Trans.). New York, NY: The Free Press (1st American ed.).

Eagly, Alice H., and Maureen Crowley. 1986. "Gender and Helping Behavior: A Meta-Analytic Review of the Social Psychological Literature." Psychological Bulletin 100(3):283-308.

Exum, M. Lyn. 2006. "Alcohol and Aggression: An Integration of Findings from Experimental Studies." Journal of Criminal Justice 34:131-45.

Fagan, Jeffery. 1990. "Intoxication and Aggression." In Crime and Justice: A Review of Research (Vol. 13). (Michael H. Tonry, Ed. And James Q. Wilson, Ed.). Chicago, IL: University of Chicago Press.

Fanti, Kostas A., Eric Vanman, Christopher C. Henrich, and Marios N. Avraamides. 2009. "Desensitization to Media Violence Over a Short Period of Time." Aggressive Behavior 35:179-87.

Felson, Richard B., Jukka Savolainen, Thoroddur Bjarnason, Amy L. Anderson, and I. Tusty Zohra. 2011. "The Cultural Context of Adolescent Drinking and Violence in 30 European Countries." American Society of Criminology 49(3):699-728.

Feshbach, N. D. 1982. "Sex Differences in Empathy and Social Behavior in Children." In The Development of Prosocial Behavior. (N. Eisenberg, Ed.). New York: Academic Press.

Furnham, A., and M. Argyle. 1981. The Psychology of Social Situations. Oxford: Pergamon Press.

Graham, Kathryn, Gail Schmidt, and Kerry Gillis. 1996. "Circumstances When Drinking Leads to Aggression: An Overview of Research Findings." Contemporary Drug Problems 23:493-551.

Griffiths, E., C. Yule, and R. Gartner. 2011. "Fighting Over Trivial Things: Explaining the Issue of Contention in Violent Altercations." Criminology 49(1):61-94.

Hindelang, Michael S., Michael Gottfredson, and James Garofalo. 1978. Victims of Personal Crime. Cambridge, MA: Ballinger.

Hoffman, M. L. 1977. "Sex Differences in Empathy and Related Behaviors." Psychological Bulletin 84:712- 22.

Huesmann, L. Rowell and Nancy G. Guerra. 1997. "Children's Normative Beliefs About Agression and Aggressive Behavior." Journal of Personality and Social Psychology 72(2):408-19. 
Kilham, W., and L. Mann. 1974. "Level of Destructive Obedience as a Function of Transmitter and Executant Roles in the Milgram Obedience Paradigm.” Journal of Personality and Social Psychology 29:696-702.

Lowe, Robert D., Mark Levine, Rachel M. Best, and Derek Heim. 2012. "Bystander Reaction to Women Fighting: Developing a Theory of Intervention." Journal of Interpersonal Violence 27(9):1802-26.

Mac an Ghaill, M. 1994. The Making of Men: Masculinities, Sexualities and Schooling. Buckingham, UK: Open University Press.

Magnusson, D. 1981. Toward a Psychology of Situations: An Interactional Perspective. Hillsdale, NJ: Erlbaum.

McAndrew, Craig, and Robert Edgerton. 1969. Drunken Comportment. Chicago, IL: Aldine. McCarry, Melanie. 2010. "Becoming a 'Proper Man': Young People’s Attitudes About Interpersonal Violence and Perceptions of Gender." Gender and Education 22(1):17-30.

Messner, Steven F. and Kenneth Tardiff. 1985. "The Social Ecology of Urban Homicide: An Application of the 'Routine Activities' Approach.” Criminology 23:241-67.

Miethe, Terance D., Mark C. Stafford, and J. Long. 1987. "Social Differentiation in Criminal Victimization: A Test of Routine Activities/Lifestyle Theories.” American Sociological Review 52(2):184-94.

Moos, R. 1973. “Conceptualizations of Human Environments.” American Psychology 28:652-65. Ng-Mak, Daisy S., Suzanne Salzinger, Richard Feldman, and Ann Stueve. 2002. "Normalization of Violence Among Inner-City Youth: A Formulation for Research.” American Journal of Orthopsychiatry 72(1):92-101.

Parker, Robert N., and Linda-Anne Rebhun. 1995. Alcohol and Homicide: A Deadly Combination of Two American Traditions. Albany: State University of New York Press.

Pervin, L. A. 1978. "Definitions, Measurements, and Classifications of Stimuli, Situations and Environments." Human Ecology 6:71-105.

Pich, Jacqueline, Michael Hazelton, Deborah Sundin, and Ashley Kable. 2010. "Patient-Related Violence Against Emergency Department Nurses.” Nursing and Health Sciences 12:26874.

Pinker, S. 2011. The Better Angels of our Nature. New York: Viking. 
Roberts, Julian, and Cynthia Benjamin. 2000. "Spectator Violence in Sports: A North American Perspective.” European Journal on Criminal Policy and Research 8:163-81.

Rossow, Ingeborg. 1996. “Alcohol-Related Violence: The Impact of Drinking Pattern and Drinking Context." Addiction 91:1651-61.

Stark, S. 2007. Coercive Control: How Men Entrap Women in Personal Life. Oxford: Oxford University Press.

Stebbins, R. A. 1981. “A Theory of the Definition of the Situation.” See Furnham and Argyle: pp. 346-62.

Vaux, A. 1985. "Variations in Social Support Associated with Gender, Ethnicity, and Age." Journal of Social Issues 41:89-110.

Virkki, Tuija. 2007. "Gender, Care, and the Normalization of Violence: Similarities Between Occupational Violence and Intimate Partner Violence in Finland." NORA-Nordic Journal of Women's Studies 15(4):220-32.

Wallington, S. A. 1973. "Consequences of Transgression: Self-Punishment and Depression." Journal of Personality and Social Psychology 28:1-7.

West Virginia University College Portrait. 2012-2013. “Fact Sheet.” College Portraits. Retrieved October 3, 2013 (http://www.collegeportraits.org/WV/WVU/characteristics).

Wolfgang, Marvin E. and Franco Ferracuti. 1967. The Subculture of Violence. London: Social Science Paperbacks. 


\section{Field Research on Fighting}

1. Your name (last name, first name):

2. For which course are you doing this research?

$\bigcirc$ socA 320 Social Psychology

SocA 311 Social Research Methods

SocA 346 Victimology

SoCA 232 Criminology

\section{Your sex:}

$\bigcirc$ Female

$\bigcirc$ Male

\section{Your age:}

5. Date of the fight (MM/DD/YYYY):

6. On what day of the week did the fight occur?
Monday
$\bigcirc$ Tuesday
$\bigcirc$ Wednesday
Thursday
$\bigcirc$ Friday
Saturday
$\bigcirc$ Sunday

\section{Time of the fight:}




\section{Field Research on Fighting}

8. Location of the fight. Name the bar, club, campus building, neighborhood, street address, nearby streets, landmarks, and any other location details.

Example: the fight began inside Bent Willey's, located on Chestnut Street in downtown Morgantown, and continued in the alley, progressing toward University Avenue.

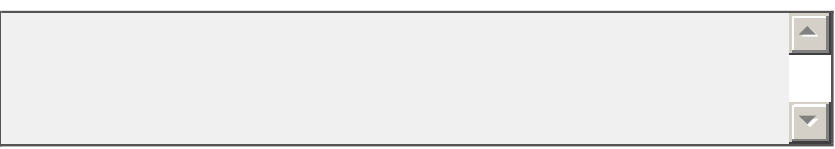

9. Describe the demographic characteristics of three key participants:

- fighters (all active participants in the fight)

- bystanders (anyone who watches or intervenes in the fight, not including authorities)

- authorities (e.g., bouncers, bartenders, police officers, university officials)

The characteristics that you should record may include the age, sex, race and any other socially relevant characteristics of these participants. If you happen to know the name of the participants, do not record this information.

Example: two white females, both around 20-25 years old, got in a fight; one white bouncer, age 20-25, broke up the fight; the crowd of bystanders included five or six people who were mostly white males who looked like undergraduate students.

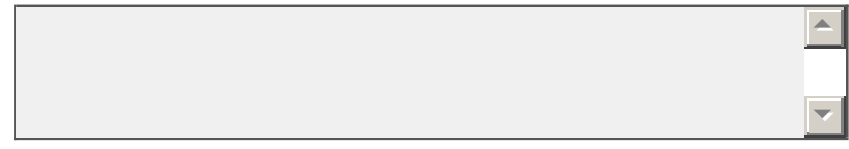

10. Did any of the participants appear drunk? What details led you to this conclusion?

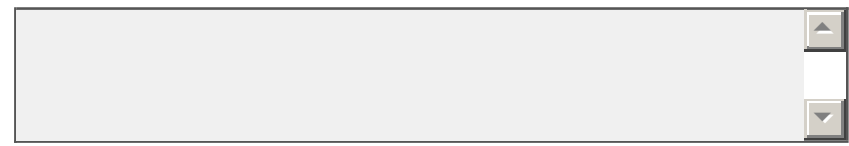




\section{Field Research on Fighting}

11. How did the fight get started? Describe any details you observe just before the fight began, such as rude remarks, yelling, spilling of beer, or throwing of objects. Make a note if you learned about how the fight started through another person or if you observed it firsthand. If you don't know how the fight began, simply enter the phrase "Don't know."

Example: I witnessed the start of the fight firsthand: before the fight began, two small groups of people were standing on an outdoor patio. A male from one of the groups began arguing with members of the other group; profane gestures and words were exchanged by both sides, including physical posturing, middle fingers, and the terms "mother fucker" and "bitch."

12. Did all the fighters seem equally responsible and willing to fight, or did one fighter (or group of fighters) clearly instigate and start harming someone who seemed, at least at first, unwilling to fight? Please explain your answer.

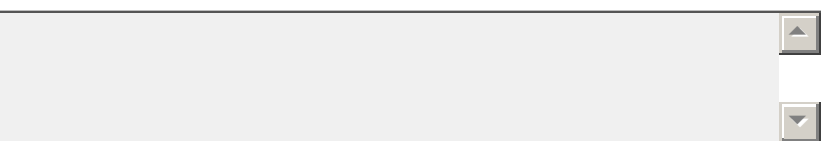

13. What happened during the fight? Describe any details you observe during the fight. Again, keep the three key actors in mind: fighters, bystanders and authorities.

Describe the type and number of aggressive acts by the fighters. How many physical contacts were there? What type of contacts (pushes, punches, kicks, choking, bites, thrown chairs, use of other objects or weapons)?

Describe how the bystanders responded. Did the bystanders encourage the fight, try to stop it, try to get away from it, scream and yell, or do nothing?

Describe the actions of the authorities. If in a bar, did bouncers attempt to stop the fight, simply push the fighters to the exit, or did they do both? How did they attempt to stop the fight? Did the bouncers punch or hurt anyone? Did they use pepper spray, a stun gun, Taser, a club, a baseball bat, or any other type of object or weapon? 


\section{Field Research on Fighting}

14. How did the fight end? Describe any details you observe at the end of the fight. Did the bouncers, police officers or bystanders stop the fight, or did the fighters stop on their own?

15. Was it a "fair fight"? Were the opposing sides equal in terms of strength and number? Please explain your answer.

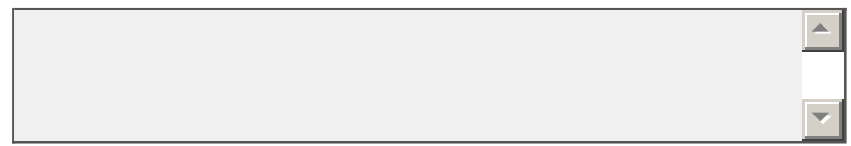

16. What were the final consequences of the fight? Did police arrive on the scene? Was there an arrest? Was someone injured? Was property damaged? Did the party end or was the bar closed down?

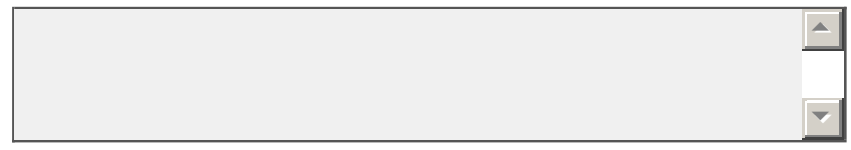

17. Finally, how did the fight affect you? Describe in detail how you felt and what you thought about the experience of observing the fight. 